\title{
Author Correction: Political dynamics and governance of World Heritage ecosystems
}

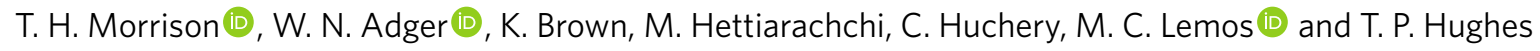

Correction to: Nature Sustainability https://doi.org/10.1038/s41893-020-0568-8, published online 20 July 2020.

In the version of this Analysis originally published, in Fig. 5b, the bottom third of the bar labelled 'Passive resistance' was mistakenly shown in white; it should have been black. All versions of the Analysis have been corrected.

Published online: 3 August 2020

https://doi.org/10.1038/s41893-020-00601-6

(c) The Author(s), under exclusive licence to Springer Nature Limited 2020 